\title{
Titration of betaine therapy to optimize therapy in an infant with 5,10-methylenetetrahydrofolate reductase deficiency
}

\author{
Sema Kalkan Ucar • Özge Altun Koroğlu • Ömer Berk • \\ Mehmet Yalaz • Nilgün Kültürsay • Henk J. Blom • \\ Mahmut Coker
}

Received: 31 March 2009/Accepted: 5 May 2009/Published online: 12 May 2009

(C) Springer-Verlag 2009

\begin{abstract}
Betaine therapy was given for 2 years to a 2year-old boy with 5,10-methylenetetrahydrofolate reductase deficiency. Used as a methyl donor to lower homocysteine levels through methylation of methionine, betaine has been reported to be effective in treating homocystinuria. Satisfactory biochemical and clinical responses were obtained with the following regimen: betaine started in the newborn period at increasing doses to reach $1 \mathrm{~g}$ given six times a day. It is suggested that frequent administration of a moderate dose may provide clinical and biochemical benefit.
\end{abstract}

Keywords Betaine $\cdot 5,10$-Methylenetetrahydrofolate reductase deficiency $\cdot$ Daily dose frequency

\section{Abbreviations \\ MTHFR methylenetetrahydrofolate reductase tHcy total plasma homocysteine}

S. K. Ucar $\cdot$ Ö. Berk $\cdot$ M. Coker

Department of Pediatrics, Ege University Medical Faculty, Izmir, Turkey

Ö. A. Koroğlu $\cdot$ M. Yalaz $\cdot$ N. Kültürsay

Department of Neonatology, Ege University Medical Faculty, Izmir, Turkey

\section{H. J. Blom}

Metabolic Unit, Department of Clinical Chemistry,

VU University Medical Center,

Amsterdam, The Netherlands

\section{S. K. Ucar $(\bowtie)$}

Department of Pediatric Endocrinology and Metabolism,

Ege University Medical Faculty,

Bornova 35100, Turkey

e-mail: semakalkan@hotmail.com

\section{Introduction}

Methylenetetrahydrofolate reductase (MTHFR) converts 5,10-methylenetetrahydrofolate to 5-methyltetrahydrofolate, which donates a methyl group to homocysteine to form methionine. MTHFR deficiency results in elevated homocysteine and low methionine levels [6]. Betaine, a methyl donor, has been shown to successfully lower plasma homocysteine and normalize methionine in MHTR patients of varying age and disease severity $[1-4,12]$. In this paper, we report an infant successfully treated with betaine, with emphasis on the frequency of administration.

\section{Case report}

A 4-kg male, the third child of consanguineous parents, was delivered at 40 weeks of gestation after an uncomplicated pregnancy. Two siblings died 28 and 16 days; the latter having a positive urinary nitroprusside reaction. Subsequently, the mother received intramuscular cyanocobalamaine (1 mg every 2 weeks) and folic acid $(5 \mathrm{mg} /$ day) during pregnancy.

On day 2, the patient developed hyperbilirubinemia, hypotonia, and lethargy. Total plasma homocysteine (tHcy) was elevated $(155.5 \mu \mathrm{mol} / \mathrm{L}[5-15 \mu \mathrm{mol} / \mathrm{L}])$ and methionine was reduced $(13.1 \mu \mathrm{mol} / \mathrm{L}[7.9-55.3 \mu \mathrm{mol} / \mathrm{L}])$. Urinary homocystine $(102 \mathrm{mmol} / \mathrm{mol}$ creatinine [0.2$4 \mathrm{mmol} / \mathrm{mol}$ creatinine]) and cystathionine $(89 \mathrm{mmol} / \mathrm{mol}$ creatinine $[0.1-3 \mathrm{mmol} / \mathrm{mol}$ creatinine]) were increased and urinary nitroprusside testing was positive. Plasma cobalamin, erythrocyte folate, and organic acid profile were normal. The metabolite pattern suggested a remethylation defect and folic acid $(10 \mathrm{mg} /$ day $)$, pyridoxine (100 mg/day), hydroxycobalamine $(1 \mathrm{mg} /$ day $)$, and carnitine $(300 \mathrm{mg} /$ day; 
Carnitine\%30, Santa Farma) were initiated. At 2 months, betaine anhydrous $(100 \mathrm{mg} / \mathrm{kg} /$ day, given every $2 \mathrm{~h}$; Cystadane ${ }^{\circledR}$, Orphan Europe) was introduced.

No enzyme activity was detectable in fibroblasts $(0 \mathrm{nmol}$ methyl tetrahydrofolate/h/mg protein), confiming a severe MHTFR deficiency and betaine was increased weekly in $50 \mathrm{mg} / \mathrm{kg}$ increments to $3 \mathrm{~g} /$ day. Each dose, mixed with formula, was given nine times per day via nasogastic tube. From 9 months to 2 years, $6 \mathrm{~g}$ betaine/day was administrated orally with meals in six divided doses, mixed with food, milk, or juice. The effects of reducing the frequency to three per day and of increasing the dose to $9 \mathrm{~g}$ /day, given three or six times, on plasma tHcy and methionine were evaluated (Fig. 1). Reducing the frequency to three per day increased tHcy from $45 \mu \mathrm{mol} / \mathrm{L}(5-15.5 \mu \mathrm{mol} / \mathrm{L})$ to around $90 \mathrm{mmol} / \mathrm{L}$ and decreased methionine levels. Increasing to more than six per day led to difficulties in administration; $6 \mathrm{~g} /$ day of betaine given in six doses provided adequate control in this patient.

Physical development was normal; however, language development and motor development were retarded by 3 to 6 months. No vaso-occlusive or thromboembolic events occurred.

\section{Discussion}

The efficacy of betaine treatment in MTHFR deficiency is established. However, dosage and frequency of administration are still controversial. One study in patients with MTHFR deficiency showed peak betaine concentration after 1 and $2 \mathrm{~h}$ with an apparent elimina- tion half-life of $1 \mathrm{~h}$ [7]. A comparison between 12 healthy males and three patients revealed an increased total plasma betaine clearance in patients, suggesting that, due to accelerated distribution and elimination kinetics, patients may require more frequent dosing to maintain plasma concentrations [8]. In this paper, mean tHcy levels of $45 \mu \mathrm{mol} / \mathrm{L}(5-15.5 \mu \mathrm{mol} / \mathrm{L})$ were achieved by administration at short intervals. This is in contrast with data indicating minimal benefit from exceeding twice-daily dosing in six patients with classical homocystinuria [5]. In healthy individuals, betaine concentrations are not affected by age and gender. However, in patients with MTHFR deficiency and classical homocystinuria, this may not be the case. Patient age, primary diagnosis, metabolic status, and duration of treatment may explain such discrepancies. There is a need for further studies of betaine in MTHFR deficiency to optimize treatment modalities.

Additionally, one therapeutic action of betaine is to increase brain methionine uptake [11]. Increasing plasma methionine concentration via optimizing betaine therapy may enhance transportation into the brain $[9,10]$.

In conclusion, more frequent administration of moderate doses of betaine in patients with MTHFR deficiency may provide clinical and biochemical benefits and should be evaluated further.

Acknowledgement We like to thank D.E.C. Smith for the excellent technical support.

Conflict of interest We have no conflict of interest.
Fig. 1 The mean total homocysteine and methionine in plasma in relation to daily dose and frequency of betaine treatment (blood samples were collected prior to administration of betaine during the last week of the each month)

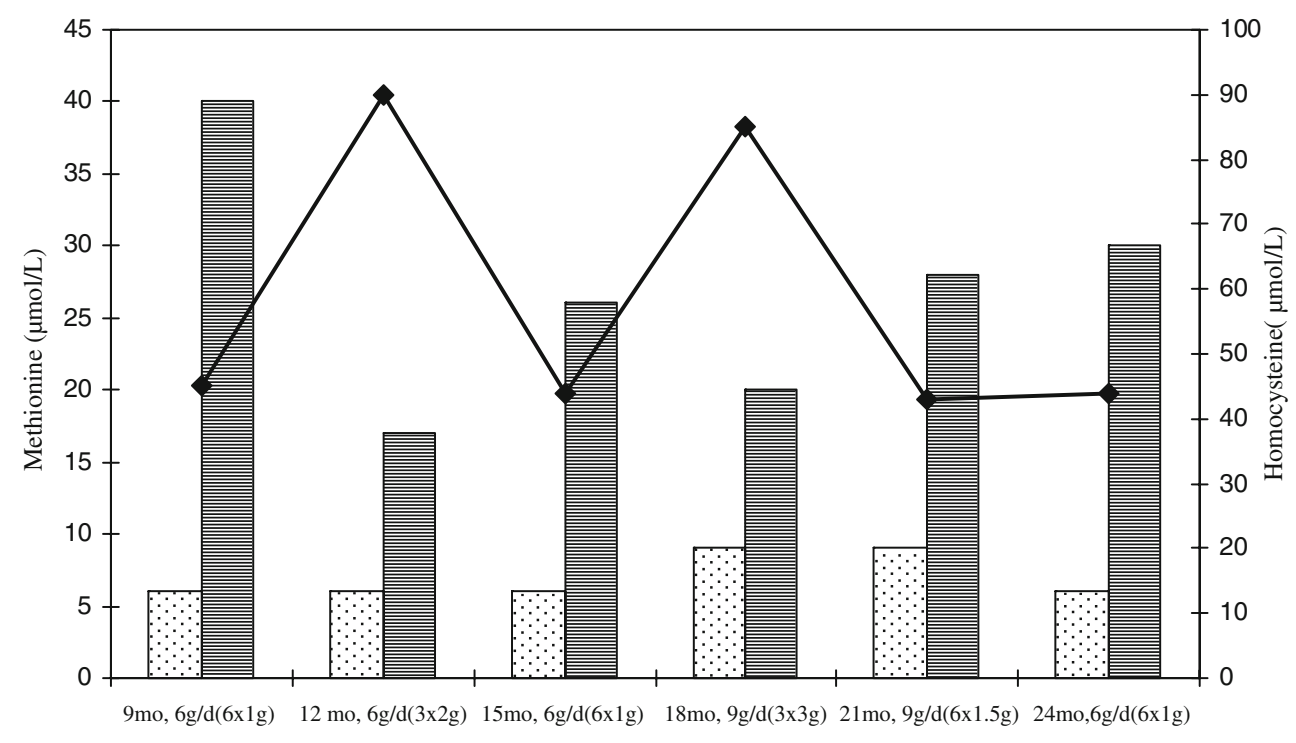

$\rightleftarrows$ Betaine(total dose/day) $\rightleftharpoons$ Methionine $(\mu \mathrm{mol} / \mathrm{L}) \multimap$ Homocysteine $(\mu \mathrm{mol} / \mathrm{L})$ 


\section{References}

1. Abeling NG, van Gennip AH, Blom H et al (1999) Rapid diagnosis and methionine administration: basis for a favourable outcome in a patient with methylene tetrahydrofolate reductase deficiency. J Inherit Metab Dis 22:240-242

2. Al Tawari AA, Ramadan DG, Neubauer D et al (2002) An early onset form of methylenetetrahydrofolate reductase deficiency: a report of a family from Kuwait. Brain Dev 24:304309

3. Holme E, Kjellman B, Ronge E (1989) Betaine for treatment of homocystinuria caused by methylenetetrahydrofolate reductase deficiency. Arch Dis Child 64:1061-1064

4. Lawson-Yuen A, Levy HL (2006) The use of betaine in the treatment of elevated homocysteine. Mol Genet Metab 88:201207

5. Matthews A, Johnson TN, Rostami-Hodjegan A et al (2002) An indirect response model of homocysteine suppression by betaine: optimising the dosage regimen of betaine in homocystinuria. $\mathrm{Br} \mathrm{J}$ Clin Pharmacol 54(2):140-146
6. Mudd SH, Uhlendorf BW, Freeman JM et al (1972) Homocystinuria associated with decreased methylenetetrahydrofolate reductase activity. Biochem Biophys Res Commun 46:905-912

7. Sakura N, Ono H, Nomura $S$ et al (1998) Betaine dose and treatment intervals in therapy for homocystinuria due to 5,10methylenetetrahydrofolate reductase deficiency. J Inherit Metab Dis 21:84-85

8. Schwahn BC, Hafner D, Hohlfeld T et al (2003) Pharmacokinetics of oral betaine in healthy subjects and patients with homocystinuria. Br J Clin Pharmacol 55(1):6-13

9. Skiba WE, Taylor MP, Wells MS et al (1982) Human hepatic methionine biosynthesis. J Biol Chem 257:14944-14948

10. Smith QR, Stoll JS (1998) Blood-brain barrier amino acid transport. In: Pardridge WM (ed) Introduction to the blood-brain barrier, vol. 1. Cambridge, Cambridge University Press, pp 188-197

11. Strauss KA, Morton DH, Puffenberger EG et al (2007) Prevention of brain disease from severe 5, 10-methylenetetrahydrofolate reductase deficiency. Mol Genet Metab 91:165-175

12. Wendel U, Bremer HI (1984) Betaine in the treatment of homocystinuria due to 5,10 -methylenetetrahydrofolate reductase deficiency. Eur J Pediatr 142:147-150 